\title{
Sponsored-Research Activities in Journalism and Mass Communication Programs
}

\author{
FRED K. BEARD
}

The extent to which the nation's J/MC programs and their faculty participate in extramural sponsored-research activities had received little research attention prior to the national survey of $J / M C$ administrators reported in this article. Findings reveal that more than $60 \%$ of the respondents' programs had produced at least one proposal for sponsored research during the year prior to the survey. Other results show (1) varying degrees of access to resources and training, (2) significant differences among $J / M C$ programs based on institutional classification, and (3) that a variety of research services and resources significantly discriminate between J/MC programs that do and do not participate in sponsored research.

The role of the U.S. professoriate changed markedly over the last twenty years as its members and their home institutions experienced increasing pressure to participate in extramural sponsored-research activities and the search for grants and other forms of external funding. College faculty participate in sponsored research for several reasons. The dollar amount of acquired grants and publication of research findings in academic journals are among the most important ways universities demonstrate the quality of their programs and faculty. ${ }^{1}$ Individual faculty members seek external funding to earn tenure and promotion and to enhance their profes- sional reputations. ${ }^{2}$ The number and quality of scholarly publications and acquired grants, in turn, increase with the number of grant proposals submitted. ${ }^{3}$

The most important reason for the increased pressure to participate in sponsored-research activities, however, is monetary. A decline in federal and private funds to support research activities throughout the 1980 s and 1990s has increased the importance of locating external funding for research universities. ${ }^{4}$ Federal funding for research in mass communication, in particular, declined substantially during the same time pe-

Fred K. Beard (FBEARD@ov.EDU) is a professor in the Gaylord College of Journalism and Mass Communication, University of Oklahoma. 
riod. ${ }^{5}$ Consequently, some scholars suggest public, nonresearch institutions (including master's and baccalaureate programs) may be experiencing pressure to seek grants to support nonresearch projects and initiatives, and that scholarly research is not necessarily inconsistent with quality undergraduate teaching. ${ }^{6}$

With the National Research Council poised to recognize Communication as one of nine social and behavioral sciences ${ }^{7}$-perhaps opening the way to greater opportunities for sponsored research in journalism and mass communication (J/MC)-it is imperative to assess how important sponsored-research has become for the nation's J/MC programs; how successful they are in participating in sponsored-research activities; and what the impact has been of various training, resources, and support services. That is the purpose of the study reported in this article, one of very few to address these important issues during the past twenty years. ${ }^{8}$

\section{Research Purpose and Questions}

The purpose of this study is to examine levels of sponsored-research activity participation in J/MC programs and the kinds of grant-related support mechanisms, policies, practices, and resources that are available to them. The study also examines relationships between institutional and faculty-level constructs of interest and participation in grant-related activities. Descriptively, the results of this study provide insight into how important external grants are for J/MC research and scholarship and provide an institutional-level performance benchmark. However, they also provide insight into how the factors that encourage and discourage faculty participation in sponsored-research activities impact programs and faculty in J/MC. Thus, the findings indicate how J/MC and university research administrators who wish to encourage faculty participation in sponsored research might most effectively do so. Finally, the results add to a growing body of research on scholarly and professional activities among J/MC faculty. ${ }^{9}$

The purposes of this study were accomplished by addressing the following research questions:

RQ1: To what extent do $\mathrm{J} / \mathrm{MC}$ programs participate in sponsored-research activities and grant acquisition?

RQ2: To what extent are financial and other resources provided at the institutional level available to support J/MC faculty participation in grant-related activities?

RQ3: To what extent are institutional practices and policies that impact grantrelated activities present on J/MC program campuses?

RQ4: To what extent are training and other services in grant development available to J/MC programs and faculty?

RQ5: What faculty beliefs, attitudes, and unitlevel policies do J/MC administrators believe exem- 
plify and influence their program's and faculty's participation in sponsored-research activities?

RQ6: To what degree and how might the institutionally funded resources; college or university policies and practices; grants training and other services; and faculty- and unitlevel beliefs, attitudes, and policies discriminate among programs that are or are not involved in sponsored-research activities?

\section{Method}

The population for this study consisted of the administrative leaders (chairs, directors, and deans) of the approximately $400 \mathrm{~J} / \mathrm{MC}$ degree programs (departments, schools, and colleges) listed in the Association for Education in Journalism and Mass Communication (AEJMC) Directory. A sample of 196 administrators was randomly selected from the Directory using interval sampling.

Sample members received an anonymous, self-administered survey questionnaire in the mail. They were asked to forward the survey packet to another administrator, such as an associate dean for research administration, if they felt there were one who could more appropriately respond to questions concerning the program's sponsored-research activities, availability of institutional resources, and faculty productivity. Survey procedures included an e-mail prenotification and an e-mail reminder. Respondents who did not return a response card indicating that they had returned a completed questionnaire received a second copy.

Administrators were asked to respond to questions regarding the nature and type of institutional resources available on their campuses. Since research on the factors that serve as incentives or disincentives to college and university faculty participation in grant-related activity first began appearing in the early- to mid-1970s, a consistent set of interdependent factors has emerged.

One of the most recent and comprehensive studies of sponsored-research activities can be found in the work of Monahan and Fortune, who surveyed a sample of administrators drawn from the National Council of University Research Administrators Directory. ${ }^{10}$ Many of the items for this study's survey questionnaire were adapted from Monahan and Fortune's study; however, several items were revised or eliminated, based on their findings and others published in the literature (e.g., Boyer and Cockriel ${ }^{11}$ ). The final questionnaire included 44 items in five sections: (1) whether programs had a sponsored-programs office or individual serving as a research administrator; (2) the extent to which financial and nonfinancial institutional resources were available to $\mathrm{J} / \mathrm{MC}$ programs and their faculty; (3) the existence of institutional policies and practices that encourage sponsored research; (4) the availability of training and other services provided by college or university grants, sponsored programs, or research administration offices; and (5) faculty- and unit-level attitudes, beliefs, policies, and descriptive variables (e.g., the highest degree offered by each program's home institution/ campus). 


\section{Findings}

The survey produced a response rate of $54 \%$ (106 usable questionnaires out of 196), after subtracting 2 "undeliverables," as recommended by Babbie and Bailey. ${ }^{12}$ The valid sample yielded a margin of error of $+/-7.2 \%$ at the $95 \%$ confidence level (when calculated using the Finite Population Correction Factor ${ }^{13}$ ). Early respondents (first $25 \%$ who responded) and late respondents (last $25 \%$ ) were tested for significant differences between mean scores on 30 of the continuous variables included on the questionnaire. The results of these comparisons revealed no statistically significant differences, indicating a reduced potential for bias attributable to nonresponse. ${ }^{14}$ As with any survey relying on the use of sampling, the findings should be interpreted with these limitations in mind.

The majority of the programs represented by respondents $(54.7 \%)$ house both J/MC and Communication disciplines, whereas most of the remainder consisted of J/MC-only programs (one respondent noted that his/her program was located in a department of English). Responding programs were housed about equally on campuses offering doctorates $(29.3 \%)$, master's $(33.0 \%)$, and baccalaureate $(37.7 \%)$ degrees.

Research Questions. RQ1 asked the following: To what extent do J/MC programs participate in sponsored-research activities and grant acquisition? Seventy $(66 \%)$ of the respondents reported that their programs and faculty had produced at least one grant proposal for sponsored research during the year prior to the survey. The largest number of proposals submitted by a single program during the fiscal year prior to the survey was 12 . A little more than one-half of the responding programs $(55,51.9 \%)$ had at least one proposal for sponsored research that had been funded. The largest number of proposals funded for an individual program was 10.

The total number of proposals submitted by all the programs that participated in sponsored-research activities was 235, for an average of about 3.4 for each participating program. The total number of proposals for sponsored research that were funded was 118 . Seventy-seven programs $(72.4 \%)$ had at least one faculty member who was actively involved in sponsored-research activities. Almost all the programs $(92.4 \%)$ had at least one faculty member who was involved in traditional scholarly research.

The difference in grant participation based on institutional classification was statistically significant. At $\mathbf{9 3 . 5} \%$, J/MC programs located on campuses where the doctorate is offered were far more likely to have faculty participating in sponsored-research activities, compared to those located on master's $(60 \%)$ and baccalaureate $(50 \%)\left(X^{2}=\right.$ 15.617 , d.f. $=2, p<.000$ ) campuses.

Administrators were dissatisfied with the levels of faculty participation in sponsored-research activities. The mean score for the following item"Faculty members are as actively involved in the pursuit of external funding as I would like them to be"-was 2.29 ( 1 = strongly disagree, $5=$ strongly agree). Interestingly, there were no significant differences based on institutional classification-administrators of programs at all three levels were about equally dissatisfied.

RQ2 asked the following: To what extent are financial and other resources provided at the institutional level avail- 
able to support J/MC faculty participation in grant-related activities? The majority of the respondents (80.2\%) indicated there was a sponsored-programs office on their campuses. Conversely, only 4 respondents reported that they had their own sponsored-programs office, and only 12 indicated that they had an individual with research administration duties.

J/MC programs located on doctorate-granting campuses are significantly more likely to report having a campuswide sponsored-programs office (96.8\%), compared to those on master's $(85.7 \%)$ and baccalaureate $(62.5 \%)\left(X^{2}\right.$ $=13.919$, d.f. $=2, p=.001$ ) campuses. Among the 12 programs that reported having an individual serving as a research administrator, 7 of them are at the doctorate institutional level, 2 are at the master's level, and 3 are at the baccalaureate level.

The availability of administrative and institutional resources is shown in Table 1. The resources that are most readily available, based on mean scores of agreement $(1=$ unavailable, $5=$ readily available), are access to equipment or technology and reduced teaching duties for faculty who have been awarded grants. The respondents disagreed that any of the other resources are readily available.

Programs affiliated with doctorategranting institutions reported statistically significantly greater agreement as to the availability of all but one of the institutional resources, when compared to baccalaureate programs-the availability of equipment and technology. However, there were few differences between programs on doctorate and master's campuses. J/MC programs on doctorate campuses, compared to those offering only the master's, reported sig- nificantly greater availability of only two resources-graduate assistants (GAs) to help faculty who have been awarded grants and additional administrative or personnel support. However, when compared to programs located on baccalaureate campuses, programs on master's campuses have significantly greater availability of merit pay, released time from teaching to prepare proposals, released time from advising to prepare proposals, released time from teaching for awarded grants, and released time from advising for awarded grants. The results of these mean comparisons and ANOVA tests of significance are shown in Table 2.

RQ3 asked the following: To what extent are institutional practices and policies that impact grant-related activities present on J/MC program campuses? The results presented in Table 3 show that respondents overall were quite neutral in their agreement regarding institutional practices and policies, with mean scores ranging between 3.18 and $3.07(1=$ strongly disagree, $5=$ strongly agree).

There were significant differences when responses to these items were analyzed by institutional classification. Administrators of $\mathrm{J} / \mathrm{MC}$ programs on doctorate campuses reported greater agreement that their institutions possess a mission statement that shows clear support for sponsored-research activities and that there is a process for returning a portion of costs associated with grants to the unit or faculty member, when compared to programs affiliated with master's and baccalaureate institutions. They reported greater agreement that there is a clearly visible and articulated recognition and reward system, although only the difference between that score and the mean for 
Table 1

Means and Standard Deviations: Administrative and Institutionally Funded Financial and Other Resources

Variable

$M^{\star} \quad$ s.d.

1. Equipment or technology (e.g., labs, computers) that are

3.95

needed by faculty to support grants or sponsored activities

2. Merit pay or other forms of personal financial compensation

for faculty who receive grants for externally sponsored projects

3. Released time from regularly assigned teaching duties for faculty to prepare proposals for grants for externally sponsored projects

4. Released time from advising and/or committee assignments

to prepare proposals for grants for externally sponsored projects

5. Reduced teaching duties for faculty who have been awarded grants for externally sponsored projects

6. Reduced student advising loads for faculty who have been awarded grants for externally sponsored projects

7. Reduced committee assignments for faculty who have been awarded grants for externally sponsored projects

8. Graduate or research assistants to help faculty in grant-seeking or grant-writing activities

9. Graduate or research assistants to help faculty who have been awarded grants for externally sponsored projects

10. Additional administrative or personnel support (e.g., secretarial help) to faculty engaged in grant development activity

${ }^{\star}$ Note: 1 = unavailable, 5 = readily available.

baccalaureate program administrators was statistically significant. There were no significant differences between master's and baccalaureate programs.

RQ4 asked the following: To what extent are training and other services in grant development available to J/MC programs and faculty? Respondents were neutral or disagreed regarding the availability of training and other services (see Table 4); however, there were significant differences when analyzed by institutional classification. Respondents representing doctorate-granting institutions reported significantly greater access to all the resources and training opportunities, when compared to baccalaureate programs. When compared to programs on master's campuses, these respondents reported significantly greater access to and provision of all the training and services, 
Table 2

Availabiltty of Administrative and Institutionally Funded

Financial and Other Resources by Institutional Classification

Dependent Measure

Doctorate Master's Baccalaureate Test

Result

1. Equipment or technology (e.g., labs, computers) that are needed by faculty to support grants or sponsored activities

$\begin{array}{cccc}4.37 & 3.86 & 3.73 & \begin{array}{c}F=2.82 \\ \text { n.s. }\end{array} \\ & & & F=10.631 \\ 3.10_{\mathrm{a}} & 2.77_{\mathrm{a}} & 1.88_{\mathrm{b}} & p<.000\end{array}$

2. Merit pay or other forms of personal financial compensation for faculty who receive grants for externally sponsored projects

3. Released time from regularly assigned teaching duties for faculty to prepare proposals for grants for externally sponsored projects

4. Released time from advising and/or committee assignments to prepare proposals for grants for externally sponsored projects

5. Reduced teaching duties for faculty who have been awarded grants for externally sponsored projects

6. Reduced student advising loads for faculty who have been awarded grants for externally sponsored projects

7. Reduced committee assignments for faculty who have been awarded grants for externally sponsored projects

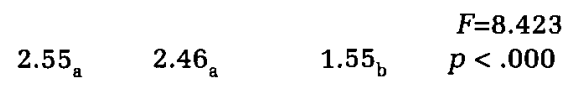

$\begin{array}{llll}2.26_{\text {a }} & 2.19_{\mathrm{a}} & 1.33_{\mathrm{b}} & F=9.855 \\ & & & \end{array}$

$3.90 \quad 3.51 \quad 2.55_{b} \quad p<.000$

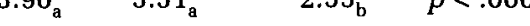

$\begin{array}{llll} & & & F=8.319 \\ \mathrm{a} & 2.46_{\mathrm{a}} & 1.72_{\mathrm{b}} & p<.000\end{array}$

$\begin{array}{llll}3.00_{\mathrm{a}} & 2.47_{\mathrm{ab}} & 2.05_{\mathrm{b}} & F=4.507 \\ & & p=.013\end{array}$

8. Graduate or research assistants to help faculty in grant-seeking or grant-writing activities

$\begin{array}{llll}2.68_{\mathrm{a}} & 2.14_{\mathrm{ab}} & 1.65_{\mathrm{b}} & \begin{array}{l}F=6.018 \\ p=.003\end{array} \\ & & & \\ 3.88_{\mathrm{a}} & 2.53_{\mathrm{b}} & 2.03_{\mathrm{b}} & \begin{array}{l}F=19.523 \\ p<.000\end{array}\end{array}$

faculty who have been awarded grants for externally sponsored projects

10. Additional administrative or personnel support (e.g., secretarial help) to faculty engaged in grant development activity

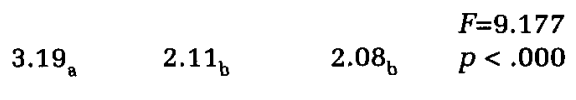

Note: Means with common subscripts are not significantly different from one another. Post hoc tests are Tukey $a$ and significant at the .05 level. $1=$ unavailable, $5=$ unavailable. 
Table 3

Means and Standard Deviations: Institutional Practices and Policies

Variable

$M^{*} \quad$ s.d.

1. There is a mission statement that shows clear support for

$3.18 \quad 1.43$

externally sponsored activities.

2. There is a clearly visible and articulated recognition and

reward system for faculty who are successful in winning grants for externally sponsored projects.

3. There is a process for returning at least a portion of the indirect

or administrative costs associated with successful grants to the

principal investigator or project director (or to the academic

departments in which these faculty are members).

*Note: 1 = unavailable, 5 = readily available.

with two exceptions-provision of editing services and access to computerized databases. Again, there were no significant differences on any of the resources or training variables between programs at the master's and baccalaureate levels.

RQ5 asked the following: What faculty beliefs, attitudes, and unit-level policies do J/MC administrators believe exemplify and influence their program's and faculty's participation in grant-related activities? Respondents clearly agreed that faculty would benefit from mentorship in the process of applying for grants and that faculty perceive too few opportunities in the J/MC disciplines (see Table 5). They also agreed somewhat that faculty perceive grantrelated activities as too time consuming, that faculty perceive traditional publication to be a safer investment of time, and that faculty pursue other opportunities and interests rather than grants. Respondents clearly disagreed they specifically recruit faculty for their skills or prior experience in proposal writing. Respondents were primarily neutral in terms of agreeing or disagreeing with the remaining items.

An analysis of these items by institutional characteristics revealed some significant differences. Respondents representing doctorate-granting institutions reported significantly greater agreement with two items, when compared to programs at both the master's and baccalaureate levels-faculty are encouraged to collaborate with other researchers and faculty are specifically recruited for their grant-writing skills and experience. Respondents located on doctorate campuses significantly disagreed that faculty consult or pursue other opportunities rather than conduct sponsored research when compared to programs in the other institutional categories. These respondents also disagreed that faculty perceive grant-related activities as too time-consuming, although only the difference between them and baccalaureate programs was significant. Similarly, respondents representing programs at both the doctor- 
Table 4

Means and Standard Deviations: Training and Other Services

Variable

$M^{*} \quad$ s.d.

1. Familiarize faculty or staff with grant opportunities

$3.09 \quad 1.15$

2. Teach faculty or staff how to locate potential sponsors

$2.62 \quad 1.22$

3. Assist in networking faculty with similar grants or research interests

$2.49 \quad 1.10$

4. Inform writers about the campus proposal approval process

$2.92 \quad 1.24$

5. Motivate faculty to engage in grant-seeking and writing

$2.75 \quad 1.08$

6. Provide editing services for proposals

$2.38 \quad 1.23$

7. Provide access to computerized on-line databases that facilitate

3.30

1.26 searches for grants and sponsored-project opportunities

8. Teach how to prepare reasonable budgets

9. Provide timely notification of grant opportunities and deadlines

${ }^{*}$ Note: 1 = unavailable, 5 = readily available.

ate and master's levels reported significantly greater agreement that faculty receive credit for sponsored-research activities in tenure and promotion decisions.

RQ6 asked the following: To what degree and how might the institutionally funded support resources; college or university policies and practices; grants training and other services; and faculty- and unit-level beliefs, attitudes, and policies discriminate among programs that are or are not involved in sponsored research activities? J/MC programs located on campuses that have a campus-wide sponsored-research office are significantly more likely to participate in sponsored-research activities $(71.8 \%)$ compared to those programs that do not have such an office $(42.9 \%)$ $\left(X^{2}=6.274\right.$, d.f. $\left.=1, p=.012\right)$. Programs that have an individual with research administration duties are also significantly more likely to participate in sponsored-research activities $(91.5 \%$ versus $62.8 \%)\left(X^{2}=3.963, d . f .=1, p=\right.$ .047). The relationship between a unit having its own sponsored-research office and participation in sponsored-research activities was not significant.

Descriptive Discriminant Analysis (DDA) ${ }^{15}$ was used to determine the degree to which the members of two groups-J/MC programs that do $(n=70)$ or do not $(n=36)$ participate in sponsored-research activities-can be differentiated using an array of discriminator variables. ${ }^{16}$ The DDA's canonical correlation coefficient $(\mathbf{R} c)$ measures the strength of the relationship between the cluster of discriminating variables and the grouping variable. The analysis also 
Table 5

Means and Standard Deviations: Faculty Beliefs, Attitudes, and Unit-Level Policies

Variable

$M^{*} \quad$ s.d.

1. Faculty have opportunities to maintain and upgrade research and technological skills through scheduled seminars or short courses.

2. Faculty are encouraged to collaborate with other researchers inside $\mathbf{3 . 2 0}$ and across departmental lines on our campus.

3. Faculty are specifically recruited for their grantwriting skills and/or prior experience in proposal writing.

4. Faculty receive significant credit for grant-related activities in tenure or promotion decisions.

5. Faculty perceive grant-related activities as too time consuming.

6. Faculty perceive too few opportunities for sponsored research in J/MC disciplines.

7. Faculty consult or pursue other entrepreneurial interests rather than conduct sponsored research.

8. Faculty perceive traditional academic research for journal

9. Many faculty would benefit from mentorship in the process of applying for grants.

${ }^{*}$ Note: 1 = unavailable, 5 = readily available.

yields standardized discriminant coefficients $(r)$ and total structure coefficients $(\beta)$ for each of the variables, both of which represent the extent to which each variable contributes to the discriminant function. Because the standardized coefficients take into account the simultaneous contributions of all the discriminant variables, which may be intercorrelated themselves, they can improperly represent each variable's unique contribution. Thus, as Klecka writes: "The perverse tendency of such situations to arise in discriminant analysis implies that the structure coefficients are a better guide to the meaning of the canonical discriminant functions than the standardized coefficients are." 17

Because of the number of variables in the present study and sample-size limitations, mean comparisons and $t$ tests were first run with program participation in sponsored activities as the independent variable and the 30 continuous discriminant variables as dependents. Twenty of the 30 discriminant variables were statistically signifi- 
Table 6

Effects of Variables Discriminating between Programs That Do and Do Not Participate in Sponsored-Research Activities

Discriminant Variable

$r$

1. Teach faculty or staff how to locate potential sponsors

2. Graduate or research assistants to help faculty who have been

awarded grants for externally sponsored projects

3. There is a mission statement that shows clear support for externally .554 sponsored activities

4. Assist in networking faculty with similar grants or research interests $\quad .534$

5. Teach how to prepare reasonable budgets

6. Motivate faculty to engage in grant-seeking and writing

7. Familiarize faculty or staff with grant opportunities

8. Equipment or technology (e.g., labs, computers) that are needed by faculty to support grants or sponsored activities

9. Inform writers about the campus proposal approval process

10. Faculty receive significant credit for grant-related activities in tenure or promotion decisions.

11. Merit pay or other forms of personal financial compensation for faculty who receive grants for externally sponsored projects

12. Graduate or research assistants to help faculty in grant-seeking or grant-writing activities

13. There is a clearly visible and articulated recognition and reward system for faculty who are successful in winning grants for externally sponsored projects.

14. Provide editing services for proposals

15. Faculty are specifically recruited for their grantwriting skills and/or prior experience in proposal writing.

16. Provide timely notification of grant opportunities and deadlines

17. Additional administrative or personnel support (e.g., secretarial help) to faculty engaged in grant development activity 
Table 6 cont.

Discriminant Variable

$r$

18. Reduced student advising loads for faculty who have been awarded grants for externally sponsored projects

19. Reduced student advising loads for faculty to prepare grants

Note: $n=100 ; \mathbf{R} c=.593 ; r=$ total structure coefficients; $\beta=$ standardized discriminant coefficients.

cantly different between the two groups $(p<.05)$. These 20 variables were then simultaneously entered into a DDA to determine the extent to which they discriminate between programs that did or did not participate in sponsored-research activities during the fiscal year prior to the survey. The discriminant function produced by the procedure was moderately correlated with J/MC program participation in sponsored research activities ( $R c=.593$ ), explained $35.2 \%$ of the variance in the group variable, and was statistically significant (Wilks' lambda $=.648, X^{2}=38.189$, d.f. $=20, p=.008$ ) (see Table 6).

The total structure coefficients in column two of Table 6 (labeled $r$ ) indicate that five training and other services variables are among the seven making the greatest statistical contributions (coefficients $>.500$ ) to the function that discriminates between J/MC programs that did or did not participate in sponsored-research activities. It is also interesting to note that an administrative and institutionally funded resource (GAs to help faculty who have been awarded grants) and an institutional policy (a mission statement showing clear support for sponsored-research activities) provided the second and third most important contributions to the function. The standardized discriminant coefficients shown in the third column of Table 6 demonstrate results similar to those obtained with the total structure coefficients. However, differences in the absolute values and signs of the coefficients, when compared to the total structure coefficients, indicate that some of the variables in the model are themselves positively or inversely correlated.

Open-Ended Responses. Some 26 of the 106 respondents replied to an open-ended request for additional insights, suggesting substantial interest in the topic. Three themes were apparent among these open-ended data.

Theme I: Institutional Classification. Open-ended responses replicate a pattern apparent in the analysis of the quantitative data-scholarly research and sponsored-research activities are much more important among J/MC programs on doctorate campuses than they are for other programs. As one administrator at the doctoral level observed: "Top priority at this institution. Research culture is very strong." A baccalaureate program administrator con- 
versely observed: "As many a teaching institution, emphasis on conducting research is minimal. Teaching excellence is the path to promotion."

There were other signs that institutional and program expectations regarding both traditional scholarly research and sponsored-research activities are strongly related to institutional classification. One master's program administrator noted: "Although our institution is NOT a research institution, scholarly activities (especially publication) have become the primary issue in tenure and promotion." Another similarly noted: "We are applying for university status. Once approved, this will all be more applicable."

Theme II: Traditional Scholarship Versus Sponsored-Research Activities. Several respondents described the appeal of traditional scholarship to their faculty members as opposed to sponsored-research activities. As one noted, "There is strong institutional support for scholarly and creative activities within department-this makes it even harder to go for non-supported grant activity." Interestingly, the administrator of a master's-level program noted that his or her faculty members would avoid sponsored research because of their philosophical approach: "Faculty in this program are somewhat wary of external grant funding for research because they are critical scholars who wish to avoid even the appearance of conflict of interest."

Theme IIr: Obstacles. The most obvious obstacle to faculty participation in sponsored-research activities is competing demands for their time and efforts. The administrator of a master's program observed: "Our teaching loads are 12 credits/4 courses per semester. Faculty are heavily involved in support- ing student organizations and service learning. Grant writing comes after traditional scholarship for most of my faculty." Another observed: "I believe that grants are important and heavily encouraged. However, very little time and assistance is available for faculty to participate in these activities. The problem is the time crunch. Most J/MC faculty are also called upon to produce news, videos, commercials, etc., for the university, in addition to teaching and research load. This leaves very little time for grants and yet the rewards for obtaining grants are higher."

Another similarly wrote: "With four-course loads, expectations for publication and service, faculty don't have or don't take time to search for grants much less apply for them. A new dean has just arrived and he has grant proposals on his screen."

\section{Discussion}

The results of this study suggest that the necessity for participating in sponsored-research activities has not gone unrecognized among the nation's J/MC administrators and their faculty colleagues. Nearly $70 \%$ of the respondents reported that their programs had at least one proposal for external funding submitted during the year prior to this study, more than half the programs had a proposal funded, and almost three-quarters had at least one faculty member actively involved in sponsored-research activities. Generalizing roughly, and within generally accepted survey research parameters, the study's findings of a $66 \%$ participation rate and an average of 3.4 submitted proposals suggest that the population of approximately 400 programs listed in the AEJMC Directory annually produce 
more than 900 proposals for sponsored research. Furthermore, other findings suggest that more than half these proposals are funded.

Unfortunately, although it seems likely that sponsored-research participation rates among many hard sciences departments and disciplines may approach $100 \%$ on research university campuses, there are limited data available among traditional hard sciences programs on master's or baccalaureate campuses, professional disciplines, or soft sciences with which to compare the findings of this study. Thus, it is difficult to conclude whether they reflect positively or negatively on J/MC programs and faculty. However, it is also noteworthy that J/MC administrators express dissatisfaction with levels of faculty participation, and they do so at all three institutional levels investigated in this study. Therefore, these findings support the conclusion that a majority of J/MC programs are participating, at least to a limited extent, in sponsored-research activities, but their administrative leaders at all institutional levels feel some pressure for their faculty to do more.

Future studies of sponsored research activities in J/MC can take advantage of the present study's results to determine to what extent progress is made. In addition, future research on this topic could usefully address how participation rates in J/MC programs compare to those in other disciplines. The history of J/MC in higher education has often been characterized by "second-class citizen" status and the threat of elimination due, in part, to two problems: (1) the somewhat unique challenge $/ / \mathrm{MC}$ programs face in meeting the expectations of two disparate groups of stakeholders-mass commu- nication practitioners and university peers; and (2) financial pressures that are forcing colleges and universities to cut programs. ${ }^{18}$ It may be that J/MC participation in sponsored-research activities compares favorably to that of other disciplines, even if levels of funded and published research do not. ${ }^{19}$ Such a finding would be useful to J/MC administrators who must promote their programs to university administrators and make the case in favor of their share of institutional resources.

Many findings of this study also support the existence of the decades-old hierarchy of institutional status from doctorate to master's to baccalaureate universities and colleges. Consequently, the findings indicate that many master's programs may also be experiencing some pressure for greater participation in sponsored research. In many cases (e.g., the availability of financial and other resources), they are much more similar to doctorate campuses than baccalaureate ones. However, despite the fact that all J/MC administrators are somewhat dissatisfied with their faculties' participation in sponsored-research activities, and that decreasing funding for higher education is also a reality on virtually all college campuses, there appear to be few expectations that faculty on baccalaureate campuses should try to find external funding to support either research- or nonresearch-related projects.

On the other hand, for administrators and faculty members who desire greater participation in sponsored-research activities, the results of the discriminant analysis indicate how this might effectively be accomplished. It seems clear, for instance, that training and grant development services provided by research administration offices 
and personnel are the most important factors. Several variables in this category are among the most influential in discriminating between programs that do or do not participate in sponsoredresearch activities, and J/MC programs on doctorate campuses consistently report greater access to them. These findings are supported by Boyer and Cockriel, ${ }^{19}$ who found that significant barriers to faculty participation are lack of training in grant seeking and grant writing, lack of knowledge in budget development, and lack of knowledge regarding funding sources. Moreover, assistance in locating sponsors and grant opportunities is especially important because the findings also show that almost all the respondents agreed that their faculty perceive there to be few opportunities in the J/MC disciplines, that scholarly publication is a safer investment of time, and that sponsored research must compete with other opportunities and entrepreneurial interests.

Future research on this topic could assess more directly faculty attitudes and beliefs about these issues. Such findings would further help administrators make a match between faculty development and faculty needs. Moreover, survey research among faculty members on this topic could also address this study's most significant limitation-the failure to explain more than $35 \%$ of the variance between participating and nonparticipating J/MC programs. Given the individualistic nature of academic life, individual-level variables would seem to offer the greatest potential for explaining more of the variance in participation in sponsored-research activities at both the program and faculty levels. Participation in sponsored-research activities operationalized in other ways-such as the dollar amounts of submitted and funded projects-might also reveal important insights.

Future research could also usefully assess the extent to which J/MC faculty obtain support in the form of intramural grants, as opposed to external sources. Although external grants are generally viewed as more prestigious and beneficial to programs, J/MC faculty may not seek external grants because they are able to compete successfully for campus resources to support their research. It would also be interesting to explore whether the pursuit of grants to support nonresearch projects, such as training programs, might be perceived as more consistent with the goals of teaching excellence, as pursued by nondoctoral institutions. Whereas grants to support activities in these areas likely contribute little to raising the status of scholarly research and productivity in $\mathrm{J} / \mathrm{MC}$ programs, they are also more in line with the interests of mass media practitioners and organizations.

\section{Endnotes}

1. Carol L. Colbeck, "The Main Reciprocal for Teaching Load: Faculty Use of Research Time" (paper presented at the annual meeting of the American Educational Research Association, Chicago, IL, March 1997).

2. Patricia Boyer and Irv Cockriel, "Factors Influencing Grant Writing: Perceptions of Tenured and Nontenured Faculty," SRA Journal 29 (1998): 61-68.

3. Boyer and Cockriel, "Factors Influencing”; John M. Mishler, "Enhancing the Prospects for Acquisition of Sponsored Funds at Small to Mid-Level Colleges and Universities: A Guide for Program Development," Research Management Review 2 (1998): 17-31. 
4. Larry M. Dooley, "Barriers and Inducements to Grant Related Activity by a College of Education Faculty" (paper presented at the annual meeting of the American Educational Research Association, New Orleans, April 1994).

5. Rasha Kamhawi and David Weaver, "Mass Communication Research Trends from 1980 to 1999," Journalism $\&$ Mass Communication Quarterly 80 (spring 2003): 7-27.

6. Colleen Donaldson, "Developing a Successful Sponsored Research Program at a 'Teaching' College," SRA Journal 23 (1991): 35-40; Dooley, "Barriers and Inducements"; Anne Sterner, "Faculty Attitudes Toward Grant-Related Activities At A Predominantly Undergraduate Institution," SRA Journal 31 (1999): 5-22.

7. The National Research Council, "Taxonomy for Research Doctorate Programs Assessment," <http://www7. nationalacademies.org/resdoc/ taxonomy.html>.

8. P. E. Isett, "Grantsmanship Faculty Committee Yields Dividends," Journalism Educator 34 (1979): 21, 64; Jian-Hua Zhu and Mark Swiencicki, "Funding for Mass Communication Research: Trends and Causes from 19541993" (paper presented at the annual meeting of AEJMC, Washington, DC, 1995).

9. David Weaver and Richard Gray, Journalism and Mass Communication Research in the United States: Past, Present and Future (Bloomington, IN: School of Journalism, Indiana University, 1979); Linda P. Morton and H. G. Chiang, "Research Productivity of Mass Communication Educators," Mass Communication Review 23 (1996): 4-16; Linda P. Morton and Fred K. Beard, "Faculty Productivity in ACEJ/MC-Accredited Programs Revisited: Tradi- tional Academic Research and Professional and Creative Activities," Southwestern Mass Communication Journal 18 (2003): 1-11.

10. Thomas C. Monahan and Jim C. Fortune, "Using Institutional Variables to Predict Success in Grants Acquisition" (paper presented at the annual meeting of the American Educational Research Association, Atlanta, GA, 1995).

11. Boyer and Cockriel, "Factors Influencing."

12. Earl Babbie, The Practice of Social Research, 5th ed. (Belmont, CA: Wadsworth, 1989); Kenneth D. Bailey, Methods of Social Research, 3d ed. (New York: The Free Press, 1986).

13. DSS, "Finite Population Correction Factor," <http://www.dssresearch. com/toolkit/resource/papers/MRM14. asp>.

14. J. Scott Armstrong and Terry S. Overton, "Estimating Nonresponse Bias in Mail Surveys," Journal of Marketing Research 14 (1977): 398-402.

15. Carl J. Huberty and Mohamed $H$. Hussein, "Some Problems in Reporting Use of Discriminant Analyses," The Journal of Experimental Education 71 (2003): 177-91.

16. Frederick Williams, Reasoning with Statistics, 3d ed. (Fort Worth, TX: Holt, Rinehart and Winston, Inc., 1986).

17. William R. Klecka, Discriminant Analysis (Beverly Hills, CA: Sage Publications, Inc., 1980), 34.

18. Fred Fedler, Arlen Carey, and Tim Counts, "Journalism's Status in Academia: A Candidate for Elimination," Journalism \& Mass Communication Educator 53 (1998): 31-39.

19. Weaver and Gray, Journalism and Mass Communication Research; Zhu and Swiencicki, "Funding for Mass Communication." 